\title{
Intimate Partner Violence Disclosure and Associated Factors Among Pregnant Women Attending a City Hospital in South-Western Uganda: A Cross-sectional Study
}

Eve Katushabe

Bishop Stuart University

John Baptist Asiimwe

Bishop Stuart University

Vincent Batwala ( $\sim$ vbatwala@must.ac.ug)

Mbarara University of Science and Technology

\section{Research Article}

Keywords: Intimate partner Violence Disclosure, Pregnancy, choice of disclosure, Uganda

Posted Date: September 9th, 2021

DOl: https://doi.org/10.21203/rs.3.rs-832337/v1

License: (c) (i) This work is licensed under a Creative Commons Attribution 4.0 International License.

Read Full License 


\section{Abstract}

Background: Pregnancy-associated Intimate Partner violence (IPV) is a significant public health problem in Uganda impacting on maternal and newborn health outcomes adversely. However, IPV disclosure and related factors among gravid women have remained poorly documented in southwestern Uganda.

Methods: In a cross-sectional design, 283 women attending Mbarara City Hospital Antenatal Clinic (ANC) were recruited into the study. The current analysis included 199 women reporting emotional, physical and sexual violence experiences through the present pregnancy.

Results: Of the 199 (70.3\%) women who experienced IPV, 99(49.7\%) disclosed it to someone. Majority (66.7\%) disclosed IPV to their family of birth, $55.5 \%$ to friends, $35.3 \%$ to husband's family member, $12.1 \%$ to neighbors, $9.1 \%$ to the healthcare providers, $8.1 \%$ to religious leaders, and $3.1 \%$ to police. Gravidity, OR= $1.9[95 \% \mathrm{Cl}: 1.07-3.31, p=0.027$ ], parity $\mathrm{OR}=1.9[95 \% \mathrm{Cl}: 1.08-3.34, p=0.026]$ and witnessed IPV OR:

5.4[95\%Cl: 1.93-14.96; $p=0.001]$ were significantly associated with IPV disclosure.

Conclusion: Half the participants disclosed their IPV experience. Majority of the women disclosed to their female family of birth and very few to healthcare workers. These findings point to the need for healthcare providers to routinely screen for IPV during antenatal care if a high IPV disclosure rate is to be achieved.

\section{Background}

Intimate Partner Violence (IPV) during pregnancy is a significant public health problem worldwide (Bailey, 2010). Precisely IPV during the prenatal period is still debatable, though it irrefutably involves many women (Van Parys et al., 2015). Globally, IPV accounts for $30 \%$ of all the violence against women aged 15 years and above (Devries et al., 2013). The prevalence of pregnancy-related IPV in sub-Saharan Africa is between 2\%-57\% (Devries et al., 2010; Shamu, Abrahams, Temmerman, Musekiwa, \& Zarowsky, 2011), but 39\% in East Africa (García-Moreno et al., 2013). In 2017, the Uganda Demographic and Health Survey (UDHS) reported that six in ten women suffered at least one of the three forms of IPV in their lifetime (UBOS, 2017). Recently in eastern Uganda, IPV of any form during pregnancy was reported as $27.8 \%$ (Epuitai, Udho, Auma, \& Nabirye, 2019). However, men are also victims of partner violence though evidence indicates that women are more susceptible (García-Moreno et al., 2013).

IPV causes great danger to the success of Safe Motherhood Initiative (Onoh et al., 2013). The mother and the fetus suffer adverse effects of IPV (Heaman, 2005; Helweg-Larsen, 2013; Koenig et al., 2010; Sanjel, 2013). Women, in general, tend to desire not to open up personal issues (also known as bedroom issues) to the public, because of the fear of shame and they lack trust in individuals within their social networks (Magnussen et al., 2011). If IPV disclosure process is appropriately conducted, it is an effective strategy to cope with the violence and results in other positive impacts on the victims (Katiti, Sigalla, Rogathi, Manongi, \& Mushi, 2016). 
However IPV disclosure remains low among women in general for instance $77.9 \%$ of the Serbian women did not disclose (Djikanović et al., 2012), in Nigeria, only 46\% disclosed IPV experience to either recognized or informal services (Okenwa, Lawoko, \& Jansson, 2009), 2009). Among pregnant women 28.6\% (Ayodapo, Sekoni, \& Asuzu, 2017) and 23.3\% (Katiti et al., 2016) did not disclose to anyone. In some cultural groups, taboos around discussing family problems with an outsider are still prohibitive (Mezey \& Bewley, 1997). Many pregnant women in abusive relationships experience shame, fear, and stigma which leads to isolation and secrecy for the victim (Murray, Crowe, \& Brinkley, 2015). The reported positive effect of IPV revelation include an end to the violence which may guarantee the wellbeing of the mother, her pregnancy, as well as impacting onto IPV strategy formulation (Montalvo-Liendo, 2009). Worldwide, IPV disclosure is projected to vary between $4 \%$ and $8 \%$ (Shah \& Shah, 2010). However, in Nigeria and Tanzania, majority of women disclosed to relatives, friends, religious leaders, or a third party (Ayodapo et al., 2017; Katiti et al., 2016). Victims of partner violence hesitate to disclose abuse to formal establishments including healthcare institutions (Githui, Chege, Wagoro, \& Mwaura, 2018). In an earlier study, pregnant women believed that screening provides the victims with the care and facts they require, they acknowledged the failure of disclosing IPV in the healthcare setting (Scholle et al., 2003). The factors identified to accelerate disclosure consist of the belief that family members and treasured friends would not be harmed when the IPV incident is reported, access to support such as housing and support groups, and a sense that privacy, desires, and aspirations would be valued in the incident of disclosing IPV(Curry et al., 2011). On the other hand involvement in communal, spiritual or partisan assemblages aided women to inform someone about the violence experienced (Katiti et al., 2016). However major reasons for failure to disclose among women in general include fear of the perpetrator, feeling uncomfortable with the health care provider and the feeling that IPV was not serious (Spangaro, Zwi, Poulos, \& Man, 2010), perceived absence of privacy, unsuitable means of probing and stigmatizing attitude from care providers (García-Moreno, Jansen, Ellsberg, Heise, \& Watts, 2005; Githui et al., 2018). The lack of trust in service providers and insufficient time in talking over IPV with ANC clients contribute to the failure of disclosure among prenatal women, (Katiti et al., 2016). Failure to disclose may predispose to maternal mental health problems (Helweg-Larsen, 2013) reduced maternal weight, increased likelihood of undergoing caesarian delivery, and maternal mortality (Koenig et al., 2010; Sanjel, 2013), and inadequate uptake of ANC (Heaman, 2005) hence an obstacle to achievement of the safe motherhood initiative (Onoh et al., 2013). On the other hand, fetal effects include premature birth and intrauterine fetal demise (Koenig et al., 2010; Sanjel, 2013). ANC visit provides an opportunity for disclosure and intervention that could reduce the adverse effects of IPV during the perinatal period (Githui et al., 2018).

The majority of women in developing countries interact with healthcare workers during ANC. In Uganda, the ANC policy recommends at least four visits during pregnancy and at least once during the postnatal period with a likelihood of continued monitoring, hence providing a perfect opportunity for reporting and discussing IPV (Devries et al., 2010). However, there is little evidence on IPV disclosure among pregnant women attending ANC in Uganda. In this setting, earlier IPV studies focused on the general population while few investigated IPV prevalence in pregnancy (Auma et al., 2020; Clarke et al., 2019; Epuitai et al., 
2019). Therefore, this study determined the IPV disclosure and associated factors among pregnant women attending a large City hospital.

\section{Methods}

\section{Study design, setting and population}

This study adopted a descriptive cross-sectional design and was conducted among antenatal women at the ANC clinic of a high-volume Mbarara City Hospital in southwestern Uganda during January 2019. The hospital operates daily general outpatient, ANC, family planning and young child clinics; and an inpatient maternity ward. The hospital database of 2018 indicated that on average, there were 800 pregnant women monthly attendance (new ANC cases and re-attendance) and they resided in and outside Mbarara City.

\section{Sample size and data collection}

A sample of 283 pregnant women was determined for recruitment following standard methods (Kish \& Sons, 1965), assuming 23.3\% disclosure as reported in Moshi Municipality of Tanzania (Katiti et al., 2016) with probability ( $p$-value) set at 0.05 .

Quantitative data collection commenced following the three-day training of two research assistants and a qualified counsellor. Data were collected using World Health Organization (WHO) study questionnaire for assessing IPV among women (García-Moreno et al., 2005), as had been used elsewhere (Ayodapo et al., 2017; Kapiga et al., 2017). A second structured questionnaire on whom the disclosure was made, was constructed based on literature. Both questionnaires in English were translated into Runyankore (the local language) and back-translated into English by a language expert.

After the routine health education sessions that start at 08:30 hours before healthcare workers start receiving clients in the ANC clinic, all women were briefed about the study. Individual interviews were conducted privately with pregnant women aged 15 to 49 years in one of the consultation rooms at the hospital after written consent. The filled questionnaires were manually checked for completeness before leaving the participants.

\section{Study variables and measures}

\section{Outcome measures}

\section{Presence of intimate partner violence}


With the WHO data collection tool, the presence of IPV stood well-defined as participants who experienced one of the three forms of IPV (psychological, physical and sexual violence). The woman stating the following: restricted from seeing friends and family members of origin, actions were done on purpose to intimidate her, having been demeaned in front of others; threatened to be injured, destined to psychological violence. Having been beaten up; punched: strangulated; intimidated with a weapon destined to physical violence. Had involuntary coitus with her partner: had coitus due to fear of what the spouse would do: having coitus in a way that was humiliating destined to sexual violence. This was reported to be effective and can distinguish the numerous types of IPV among individuals (Schraiber, Latorre, França Jr, Segri, \& d'Oliveira, 2010).

\section{IPV disclosure}

The primary outcome was IPV disclosure that was measured as a binary variable (Yes/No).

\section{Data Management and analysis}

The filled questionnaires were cleaned before data entry in EpiData 3.1 software (The EpiData Association, Odense, Denmark) and analysed in STATA (v.14, Stata Corp. LP, College Station, Texas, USA) for analysis. Univariate followed by bivariate analyses were carried out.

\section{Results}

\section{Socio-demographic and Clinical Characteristics of Pregnant Women}

Overall 283 ANC women who attended Mbarara City Hospital during January 2019 were recruited into the study (Table 1). Approximately $50.2 \%$ were aged $20-24$ years with the youngest and eldest being 15 and 49 years old, respectively. The same proportion of participants $(50.2 \%)$ was in the second trimester. Again $51.6 \%$ were carrying their first pregnancy. Some $54.8 \%$ had never had any child before and this included the first pregnancy and those who had miscarriage. The majority (93.6\%) were living with their sexual partners. Only $71 \%$ intended to conceive the current pregnancy. Again $50.2 \%$ were Anglicans, $38.9 \%$ Catholic, 9.5\% Muslim while the rest belonged to minority religious groups that included Seventh Day Adventists (SDA). The study setting being their home district, the Banyankore ethnic group constituted the majority $(72.8 \%)$. Regarding employment, $41 \%$ was self-employed. Some $(44.5 \%)$ participants attained secondary education. Meanwhile, $92.9 \%$ were not alcohol users.

Table 1

Socio-Demographic and Clinical Characteristics of Study Participants 


\begin{tabular}{|c|c|}
\hline Variable & $n(\%)$ \\
\hline Age in years & $24.58 \pm 4.33^{\star}$ \\
\hline $15-19$ & $23(8.1)$ \\
\hline $20-24$ & $142(50.2)$ \\
\hline $25-29$ & $83(29.3)$ \\
\hline $30-34$ & $29(10.3)$ \\
\hline$\geq 35$ & $6(2.2)$ \\
\hline \multicolumn{2}{|c|}{ Trimester at time of interview } \\
\hline $1^{\text {st }}$ & $15(5.3)$ \\
\hline $2^{\text {nd }}$ & $142(50.2$ \\
\hline $3^{\text {rd }}$ & $126(44.5)$ \\
\hline Gravidity & $1.82 \pm 1.04^{*}$ \\
\hline 1 & $146(51.6)$ \\
\hline 2 & $71(25.1)$ \\
\hline 3 & $46(16.3)$ \\
\hline$\geq 4$ & $20(7)$ \\
\hline Parity & $0.77 \pm 1.05^{\star}$ \\
\hline None & $155(54.8)$ \\
\hline 1 & $69(24.4)$ \\
\hline 2 & $38(13.4)$ \\
\hline 3 & $13(4.6)$ \\
\hline 4 & $7(2.4)$ \\
\hline$\geq 5$ & $1(0.4)$ \\
\hline \multicolumn{2}{|c|}{ Intended pregnancy } \\
\hline Yes & 201(71) \\
\hline No & $82(28.9)$ \\
\hline \multicolumn{2}{|l|}{ Religion } \\
\hline Anglican & $140(50.2)$ \\
\hline
\end{tabular}




\begin{tabular}{|ll|}
\hline Catholic & $109(38.9)$ \\
\hline Muslim & $27(9.5)$ \\
\hline Seventh-Day Adventist & $4(1.4)$ \\
\hline Others & $3(1.1)$ \\
\hline Tribe & \\
\hline Munyankore & $206(72.8)$ \\
\hline Mukiga & $39(13.8)$ \\
\hline Muganda & $24(8.5)$ \\
\hline Others & $14(5)$ \\
\hline Marital status & \\
\hline Living with a partner & $265(93.6)$ \\
\hline Separated & $14(5)$ \\
\hline Single & $4(1.4)$ \\
\hline Occupation & \\
\hline Salaried job & $20(7.1)$ \\
\hline Self-employed & $263(92.9)$ \\
\hline Not employed & $107(23.7)$ \\
\hline Education level & $116(41)$ \\
\hline No formal education & $100(35.3)$ \\
\hline Primary & \\
\hline Secondary & \\
\hline Tertiary & \\
\hline Alcohol consumption & \\
\hline Yes & \\
\hline No & \\
\hline N & \\
\hline
\end{tabular}




\section{The IPV prevalence}

Out of the 283 pregnant women enrolled, 199(70.3\%) had experienced some form of IPV in their current prenatal period (Table 2). Psychological IPV was the most prevalent (38.2\%). None of them had experienced exclusively physical violence. The majority had both psychological and sexual violence (22.3\%) and $3.5 \%$ experienced all the forms of IPV.

Table 2

Prevalence and forms of IPV among pregnant women

\begin{tabular}{|ll|}
\hline Variable(N=283) & $n(\%)$ \\
\hline Experienced IPV & $199(70.3)$ \\
\hline Forms of IPV & \\
\hline One & $108(38.2)$ \\
\hline Psychological & $9(3.2)$ \\
\hline Sexual violence & $0(0)$ \\
\hline Physical violence & \\
\hline Two & $63(22.3)$ \\
\hline Psychological plus Sexual & $8(2.8)$ \\
\hline Psychological plus Physical & $1(0.4)$ \\
\hline Physical plus Sexual & \\
\hline Three & $10(3.5)$ \\
\hline Psychological plus Physical plus Sexual
\end{tabular}

\section{The Prevalence of IPV Disclosure}

Out of 199 women who experienced violence in the current pregnancy, 99(49.7\%) told a third person about it (Table 3). Most of the participants informed a supporter from their family of origin (66.7\%) and only $(9.1 \%)$ disclosed to healthcare providers.

Table 3

The Prevalence of IPV Disclosure 


\begin{tabular}{|lll|}
\hline Variable & Disclosure \\
\hline & Yes $n(\%)$ & No $n(\%)$ \\
\hline Overall & $99(49.7)$ & $100(50.3)$ \\
\hline Person of Disclosure* & & \\
\hline Health worker & $9(9.1)$ & $90(90.9)$ \\
\hline Husband's birth family & $35(35.3)$ & $64(64.6)$ \\
\hline Woman's family of origin & $66(66.7)$ & $33(33.3)$ \\
\hline Neighbor & $12(12.1)$ & $87(87.9)$ \\
\hline Religious leader & $3(3)$ & $96(97)$ \\
\hline Woman's Friends & $51(55.5)$ & $48(48.5)$ \\
\hline Police & $8(8.1)$ & $91(91.9)$ \\
\hline Others & $3(3)$ & $96(97)$ \\
\hline *Multiple response questions & \\
\hline
\end{tabular}

Reasons for disclosure of IPV experience among pregnant women

\begin{tabular}{|lll|}
\hline Variable & Frequency* & Percentage (\%) \\
\hline To access support & 108 & 96.5 \\
\hline needs and wishes would be respected & 82 & 73.2 \\
\hline Personal safety & 78 & 69.6 \\
\hline Could not endure any more & 76 & 67.9 \\
\hline Keeping other family members/loved ones safe & 39 & 34.8 \\
\hline Threatened or tried to kill me & 25 & 22.3 \\
\hline Saw that children were suffering & 17 & 15.2 \\
\hline *Multiple responses & & \\
\hline
\end{tabular}

The majority of the participants wanted to disclose to access support (96.5\%) and the minority $15.2 \%$ disclosed because they saw their children suffering.

\section{Factors associated with IPV disclosure among pregnant women}


From table 4 below, experiencing IPV in the presence of someone accounted for five times the likelihood of disclosing than those experiencing it in absence of a third person ( $\mathrm{OR}=5.7,95 \% \mathrm{Cl}: 2.09-15.83, p=$ $0.001)$. Women who had had two or more pregnancies were 1.9 times more likely to disclose than those with the first pregnancy $(\mathrm{OR}=1.9,95 \% \mathrm{Cl}: 1.07-3.31, p=0.027)$. Again women with one or more children were 1.9 times more likely to disclose than those who had never had a child $(\mathrm{OR}=1.9,95 \% \mathrm{Cl}: 1.08-3.34$, $p=0.026)$.

Table 4

Bivariate analysis of factors influencing IPV disclosure among pregnant women 


\begin{tabular}{|c|c|c|c|c|c|}
\hline \multirow{2}{*}{$\begin{array}{l}\text { Variable } \\
\text { N=199 }\end{array}$} & & \multicolumn{2}{|l|}{ Disclosure } & \multirow[t]{3}{*}{ UOR $(95 \% \mathrm{Cl})$} & \multirow{3}{*}{$\begin{array}{l}p- \\
\text { value }\end{array}$} \\
\hline & & Yes, & No, & & \\
\hline & & $\mathrm{n}(\%)$ & $\mathrm{n}(\%)$ & & \\
\hline \multirow[t]{2}{*}{ Age (years) } & $15-29$ & $84(48 \%)$ & $91(52 \%)$ & 1.0 & \multirow[t]{2}{*}{0.180} \\
\hline & $30+$ & $15(62.5 \%)$ & $9(37.5 \%)$ & $\begin{array}{l}1.8(0.75- \\
4.34)\end{array}$ & \\
\hline \multirow[t]{3}{*}{ Trimester at time of interview } & $1 \mathrm{st}$ & $4(40 \%)$ & $6(60 \%)$ & 1.0 & \multirow[t]{3}{*}{0.799} \\
\hline & 2nd & $48(49.5)$ & $49(50.5)$ & $\begin{array}{l}1.5(0.39- \\
5.54)\end{array}$ & \\
\hline & $3 r d$ & $47(51.1)$ & $45(48.9)$ & $\begin{array}{l}1.6(0.41- \\
5.92)\end{array}$ & \\
\hline \multirow[t]{2}{*}{ Gravidity } & $\begin{array}{l}\text { First } \\
\text { pregnancy }\end{array}$ & $46(42.9)$ & $61(57.0)$ & 1.0 & \multirow[t]{2}{*}{$0.027 *$} \\
\hline & $\begin{array}{l}\geq 2 \\
\text { pregnancies }\end{array}$ & )$^{54(58.7)}$ & $38(41.3)$ & $\begin{array}{l}1.9(1.07- \\
3.31)\end{array}$ & \\
\hline \multirow[t]{2}{*}{ Parity } & None & $48(43.2)$ & $63(56.8)$ & 1.0 & \multirow[t]{2}{*}{$0.026 *$} \\
\hline & $\geq 1$ & $52(59.1)$ & $36(40.9)$ & $\begin{array}{l}1.9(1.08- \\
3.34)\end{array}$ & \\
\hline \multirow[t]{2}{*}{ Intended pregnancy } & Yes & 63(46.7\%) & 72(53.3\%) & 1.0 & \multirow[t]{2}{*}{0.207} \\
\hline & No & $36(56.3 \%)$ & $28(43.8 \%)$ & $\begin{array}{l}0.7(0.37- \\
1.24)\end{array}$ & \\
\hline \multirow[t]{3}{*}{ Religion } & Catholics & $43(57.3)$ & 32 & 1.0 & \multirow[t]{3}{*}{0.206} \\
\hline & Anglican & $47(48)$ & $51(52)$ & $\begin{array}{l}0.7(0.37- \\
1.26)\end{array}$ & \\
\hline & Others & $10(38.5)$ & $16(61.5)$ & $\begin{array}{l}0.5(0.19- \\
1.16)\end{array}$ & \\
\hline \multirow[t]{2}{*}{ Tribe } & Munyankore & $75(52.5 \%)$ & $68(47.6 \%)$ & 1.0 & \multirow[t]{2}{*}{0.322} \\
\hline & Others & $25(44.6)$ & $31(55.4)$ & $\begin{array}{l}0.7(0.39- \\
1.36)\end{array}$ & \\
\hline \multirow[t]{2}{*}{ Marital status } & $\begin{array}{l}\text { Living with } \\
\text { partner }\end{array}$ & $92(49.5)$ & $94(50.5)$ & 1.0 & \multirow[t]{2}{*}{0.4} \\
\hline & $\begin{array}{l}\text { Not living } \\
\text { with partner }\end{array}$ & $8(61.5)$ & $5(38.5)$ & $\begin{array}{l}1.1(0.60- \\
1.91)\end{array}$ & \\
\hline
\end{tabular}




\begin{tabular}{|c|c|c|c|c|c|}
\hline \multirow[t]{2}{*}{ Occupation } & $\begin{array}{l}\text { Gainfully } \\
\text { employed }\end{array}$ & $63(49.6)$ & $64(50.4)$ & 1.0 & \multirow[t]{2}{*}{0.809} \\
\hline & $\begin{array}{l}\text { Not } \\
\text { employed }\end{array}$ & $37(51.4)$ & $35(48.6)$ & $\begin{array}{l}1.1(0.60- \\
1.91)\end{array}$ & \\
\hline \multirow[t]{2}{*}{ Education level } & $\begin{array}{l}\text { None or } \\
\text { primary } \\
\text { education }\end{array}$ & $25(52.0)$ & $24(49)$ & 1.0 & \multirow[t]{2}{*}{0.901} \\
\hline & $\begin{array}{l}\text { Secondary } \\
\text { and above }\end{array}$ & $45(51.1)$ & $43(48.9 \%)$ & $\begin{array}{l}0.9(0.50- \\
1.83)\end{array}$ & \\
\hline \multirow[t]{2}{*}{$\begin{array}{l}\text { Communication to the family of } \\
\text { birth/partner }\end{array}$} & $\begin{array}{l}\text { At least } \\
\text { once a week }\end{array}$ & $86(51.5)$ & $81(48.5)$ & 1.0 & \multirow[t]{2}{*}{0.422} \\
\hline & $\begin{array}{l}\text { Once a } \\
\text { month and } \\
\text { above }\end{array}$ & $14(43.8)$ & $18(56.3)$ & $\begin{array}{l}0.7(0.34- \\
1.57)\end{array}$ & \\
\hline \multirow[t]{3}{*}{ Forms of violence } & One form & $67(57.3)$ & $50(42.7)$ & 1.0 & \multirow[t]{3}{*}{0.061} \\
\hline & Two forms & $29(40.3)$ & $43(59.7)$ & $\begin{array}{l}1.9(1.05- \\
3.48)\end{array}$ & \\
\hline & Three forms & $4(40)$ & $6(60)$ & $\begin{array}{l}1.9(0.52- \\
7.24)\end{array}$ & \\
\hline \multirow[t]{2}{*}{ Witnessed IPV } & No & $77(45)$ & $94(55)$ & 1.0 & \multirow[t]{2}{*}{0.001 * } \\
\hline & Yes & $23(82.1 \%)$ & $5(17.9)$ & $\begin{array}{l}5.7(2.03- \\
15.46)\end{array}$ & \\
\hline
\end{tabular}

\section{Discussion}

Intimate Partner Violence disclosure and the factors associated with the disclosure among pregnant women attending a City Hospital in Southwestern Uganda was determined. Key findings indicate that $70.3 \%$ of participants were victims of IPV (including psychological, sexual, and or physical) of whom only 49.7\% disclosed their IPV experience. This proportion of disclosure was higher than that observed in Tanzania (23.3\%) (Katiti et al., 2016), Nigeria 46\% (Okenwa et al., 2009), Dhaka 21\% (Parvin, Sultana, \& Naved, 2016) but similar to that reported in Ethiopia 51.4\% (Agenagnew, Tebeje, \& Tilahun, 2020) and. The higher rate of IPV disclosure reported here may be attributed to the perceived assurance of confidentiality by those they disclosed to and in such cases, the majority disclosed to their family origin considering them as very good at keeping secrets as well as providing constructive marital guidance. Indeed, an earlier study (Sigalla et al., 2017) reported that women disclose affiliation trials to their kinfolk and this, in turn, encouraged them to remain in the abusive relationships (McCleary-Sills et al., 2016).

For the majority of the women (66.7\%), IPV disclosure was to the kinfolk. These results are comparable with a Nigerian study wherein, an equivalent proportion of women (68\%) expressed the readiness of IPV 
disclosure to the kinsfolk (Okenwa et al., 2009). The probable reason for IPV victims to prefer disclosing to the kinfolk might be due to the solid personal connection between them, unlike other society members who tend to enact stigma and embarrassment upon the victim-survivors. A study in Tanzania explained IPV as being highly normalized, victims are made quiet by their fright of social consequences, the fright reinforced by the acceptance that it is women's IPV disclosure that conveys embarrassment, instead of the perpetrator's violent act (McCleary-Sills et al., 2016). Earlier research showed that the victim's in-laws and friends of the violent intimate partner were least supportive (Rizo \& Macy, 2011). Women are respected by in-laws and therefore such respect impacts onto their ability to disclose to the husband's family members (McCleary-Sills et al., 2016). Other studies have associated fear of revenge, not wanting to get the perpetrator into trouble, the feeling that the situation was not worth reporting and to keep the situation more private as factors promoting IPV disclosure to the woman's family (Ayodapo et al., 2017)

Surprisingly in the current study, only $9.1 \%$ disclosed IPV experience to healthcare providers. This rate is lower than that reported in Serbia (25.7\%) (Djikanović et al., 2012), but it is unacceptably low considering that pregnancy increases women's contact with healthcare staff particularly midwives who provide valuable information to benefit both the mother and her fetus. This low rate of disclosure may be explained by the sociocultural belief that women must keep secret their intimate partner problems. Indeed one study reported that IPV victims perceived conjugal difficulties as their own (Hegarty \& Taft, 2001). These pregnant women experiencing IPV need counseling services because of the adverse effects on the fetus and the mother. If disclosure to the healthcare providers increases then IPV associated complications would be reduced. Already a Nigerian study reported that social support was associated with reduced adverse consequences for IPV victims and their quality of life greatly improved (Ayodapo et al., 2017). IPV screening in health facilities points to early IPV detection (De Boinville, 2013) and IPV disclosure is an indispensable step in guaranteeing reassurance healthcare service providers, seeking out safe refuge and attaining lawful protection (Sylaska, 2014).

The current findings revealed that women who experienced violence in the presence of a third party were more likely to disclose, and echoes that reported in the United States of America (Sylaska, 2014). It is possible that the witness provides courage, confidence and guidance for the victim to seek support elsewhere. Previous research reported motivation for IPV disclosure as having children in the violent relationship (Agenagnew et al., 2020; García-Moreno et al., 2005; Parvin et al., 2016). This could be attributed to the women's fear of IPV effect on their children since they might also be threatened or hit by the perpetrator during the scuffle. Pregnant women who had children were more likely to disclose than those who had none. It is natural for women to feel uncomfortable when children are suffering more so women can feel guilty due to the thought of themselves contributing to the suffering as they are directly involved in the violent relationship.

\section{Recommendations}


Currently in Uganda, there is no recommended strategy in clinical practice targeting IPV. This denotes that majority of victims will remain suffering the already reported preventable yet fatal consequences of IPV. Therefore as a policy, screening of IPV should be incorporated in the Clinical Guidelines that should routinely be carried out during prenatal care to detect and appropriately manage potential IPV cases as early as possible.

\section{Limitation}

Since IPV is culturally a sensitive issue in Uganda, there is a possibility that participants provided socially desired responses. However, this was minimized by ensuring anonymity, confidentiality, training interviewers about empathy, and use of private room during interview.

\section{Conclusion}

The IPV burden in this clinical setting is very high and widespread among pregnant women, however, about half of them disclosed their IPV experience. Pregnant women preferred IPV disclosure to their kinfolk and less to healthcare providers. Hence, there is a very high rate of IPV experience with lower disclosure patterns in Mbarara City Hospital in southwestern Uganda, which eventually may have adverse physical, social, and emotional effects on the pregnant women if no intervention is put in place.

\section{Abbreviations}

ACOG: American College of Obstetricians and Gynecologists

ANC: Antenatal Care

FGD: Focused Group Discussion

IPV: Intimate Partner Violence

SDG: Sustainable Development Goal

UDHS: Uganda Democratic Health Survey

WHO: World Health Organization

\section{Declarations}

\section{- Ethics authorization and consent to participate}


The study was reviewed and cleared by Mbarara University of Science and Technology (MUST) Faculty of Medicine Research Committee (Ref: DMS 6) as well as MUST Research Ethics Committee (Ref: MUREC 1/7). MUREC is accredited by Uganda National Council for Science and Technology, and is recognized internationally and received accreditation from the United States Federal Wide Assurance (FWA00007740). Therefore, all methods were carried out in accordance with relevant national and international guidelines and regulations. Each participant signed an informed consent form at the time of enrollment.

\section{- Consent for publication}

Not relevant

\section{- Data availability}

The dataset used this research is available from the corresponding author on reasonable request.

\section{- Conflicts of Interest}

None declared.

\section{- Funding}

This research was funded by the First Mile Community Health Program of the Community Health Department, Mbarara University of Science and Technology.

\section{- Authors' contribution}

KE and BV designed the study. KE took part in data collection, data analysis, and drafted the manuscript. AJB drafted the manuscript. BV advised on data entry, analysis in addition to manuscript review for logical content. All authors read and sanctioned the final manuscript.

\section{- Acknowledgment}

We recognize the support of the Community Health Department, Mbarara University of Science and Technology as well as the data collectors and study participants for providing the information. 


\section{References}

1. Agenagnew, L., Tebeje, B., \& Tilahun, R. (2020). Disclosure of intimate partner violence and associated factors among victimized women, Ethiopia, 2018: a community-based study. International journal of reproductive medicine, 2020.

2. Auma, A. G., Ayebare, E., Olwit, C., Ndeezi, G., Nankabirwa, V., \& Tumwine, J. K. (2020). Intimate partner violence among pregnant teenagers in Lira district, northern Uganda: a cross-sectional study. African Journal of Midwifery and Women's Health, 14(4), 1-11.

3. Ayodapo, A. O., Sekoni, O. O., \& Asuzu, M. C. (2017). Pattern of intimate partner violence disclosure among pregnant women attending ante-natal clinic in Oyo East Local Government, Nigeria. South African Family Practice, 59(2), 67-71.

4. Bailey, B. A. (2010). Partner violence during pregnancy: prevalence, effects, screening, and management. International journal of women's health, 2, 183.

5. Clarke, S., Richmond, R., Black, E., Fry, H., Obol, J. H., \& Worth, H. (2019). Intimate partner violence in pregnancy: a cross-sectional study from post-conflict northern Uganda. BMJ open, 9(11), e027541.

6. Curry, M. A., Renker, P., Robinson-Whelen, S., Hughes, R. B., Swank, P., Oschwald, M., \& Powers, L. E. (2011). Facilitators and barriers to disclosing abuse among women with disabilities. Violence and victims, 26(4), 430-444.

7. De Boinville, M. (2013). Screening for domestic violence in health care settings. Washington, DC: US Department of Health and Human Services.

8. Devries, K. M., Kishor, S., Johnson, H., Stöckl, H., Bacchus, L. J., Garcia-Moreno, C., \& Watts, C. (2010). Intimate partner violence during pregnancy: analysis of prevalence data from 19 countries. Reproductive health matters, 18(36), 158-170.

9. Devries, K. M., Mak, J. Y., Garcia-Moreno, C., Petzold, M., Child, J. C., Falder, G., . . Rosenfeld, L. (2013). The global prevalence of intimate partner violence against women. Science, 340(6140), 15271528.

10. Djikanović, B., Lo Fo Wong, S., Jansen, H. A., Koso, S., Simić, S., Otašević, S., \& Lagro-Janssen, A. (2012). Help-seeking behaviour of Serbian women who experienced intimate partner violence. Family Practice, 29(2), 189-195.

11. Epuitai, J., Udho, S., Auma, A. G., \& Nabirye, R. C. (2019). Intimate partner violence among pregnant women in Uganda. African Journal of Midwifery and Women's Health, 13(2), 1-5.

12. García-Moreno, C., Jansen, H. A., Ellsberg, M., Heise, L., \& Watts, C. (2005). WHO multi-country study on women's health and domestic violence against women: World Health Organization.

13. García-Moreno, C., Pallitto, C., Devries, K., Stöckl, H., Watts, C., \& Abrahams, N. (2013). Global and regional estimates of violence against women: prevalence and health effects of intimate partner violence and non-partner sexual violence: World Health Organization.

14. Githui, S., Chege, M., Wagoro, M. C., \& Mwaura, J. (2018). Nurse's Perception on Non-Disclosure of Intimate Partner Violence by Pregnant Women: A Cross-Sectional Study. International Journal of 
Contemporary Research and Review, 9(1).

15. Heaman, M. I. (2005). Relationships between physical abuse during pregnancy and risk factors for preterm birth among women in Manitoba. Journal of Obstetric, Gynecologic, \& Neonatal Nursing, 34(6), 721-731.

16. Hegarty, K. L., \& Taft, A. J. (2001). Overcoming the barriers to disclosure and inquiry of partner abuse for women attending general practice. Australian and New Zealand journal of public health, 25(5), 433-437.

17. Helweg-Larsen, K. (2013). Violence against women in Europe: magnitude and the mental health consequences described by different data sources Violence against women and mental health (Vol. 178, pp. 54-64): Karger Publishers.

18. Kapiga, S., Harvey, S., Muhammad, A. K., Stöckl, H., Mshana, G., Hashim, R., . . Watts, C. (2017). Prevalence of intimate partner violence and abuse and associated factors among women enrolled into a cluster randomised trial in northwestern Tanzania. BMC Public Health, 17(1), 190.

19. Katiti, V., Sigalla, G. N., Rogathi, J., Manongi, R., \& Mushi, D. (2016). Factors influencing disclosure among women experiencing intimate partner violence during pregnancy in Moshi Municipality, Tanzania. BMC Public Health, 16(1), 715.

20. Kish, L. J. S. S. N. Y. J. W., \& Sons, I. (1965). Some issues of inference from survey data. 574-597.

21. Koenig, M. A., Stephenson, R., Acharya, R., Barrick, L., Ahmed, S., \& Hindin, M. (2010). Domestic violence and early childhood mortality in rural India: evidence from prospective data. International Journal of Epidemiology, 39(3), 825-833.

22. Magnussen, L., Shoultz, J., Richardson, K., Oneha, M. F., Campbell, J. C., Matsunaga, D. S., . . . Manzano, H. (2011). Responding to the Needs of Culturally Diverse Women Who Experience Intimate Partner Violence Who Experience Intimate Partner Violence. Hawaii medical journal, 70(1), 9.

23. McCleary-Sills, J., Namy, S., Nyoni, J., Rweyemamu, D., Salvatory, A., \& Steven, E. (2016). Stigma, shame and women's limited agency in help-seeking for intimate partner violence. Global public health, 17(1-2), 224-235.

24. Mezey, G. C., \& Bewley, S. (1997). Domestic violence and pregnancy: Risk is greatest after delivery: British Medical Journal Publishing Group.

25. Montalvo-Liendo, N. (2009). Cross-cultural factors in disclosure of intimate partner violence: an integrated review. Journal of Advanced Nursing, 65(1), 20-34.

26. Murray, C. E., Crowe, A., \& Brinkley, J. (2015). The stigma surrounding intimate partner violence: A cluster analysis study. Partner abuse, 6(3), 320-336.

27. Okenwa, L., Lawoko, S., \& Jansson, B. (2009). Factors associated with disclosure of intimate partner violence among women in Lagos, Nigeria. Journal of injury and violence research, 1(1), 37.

28. Onoh, R., OUJ, U., Ezeonu, P., Onyebuchi, A., Lawani, O., \& Agwu, U. (2013). Prevalence, pattern and consequences of intimate partner violence during pregnancy at Abakaliki Southeast Nigeria. Annals of medical and health sciences research, 3(3), 484-491. 
29. Parvin, K., Sultana, N., \& Naved, R. T. (2016). Disclosure and help seeking behavior of women exposed to physical spousal violence in Dhaka slums. BMC Public Health, 16(1), 1-8.

30. Rizo, C. F., \& Macy, R. J. (2011). Help seeking and barriers of Hispanic partner violence survivors: A systematic review of the literature. Aggression and Violent Behavior, 16(3), 250-264.

31. Sanjel, S. (2013). Gender-based violence: a crucial challenge for public health. Kathmandu University medical journal, 11(2), 179-184.

32. Scholle, S. H., Buranosky, R., Hanusa, B. H., Ranieri, L., Dowd, K., \& Valappil, B. (2003). Routine screening for intimate partner violence in an obstetrics and gynecology clinic. American journal of public health, 93(7), 1070-1072.

33. Schraiber, L. B., Latorre, M. d. R. D. O., França Jr, I., Segri, N. J., \& d'Oliveira, A. F. P. L. (2010). Validity of the WHO VAW study instrument for estimating gender-based violence against women. Revista de saude publica, 44(4), 658-666.

34. Shah, P. S., \& Shah, J. (2010). Maternal exposure to domestic violence and pregnancy and birth outcomes: a systematic review and meta-analyses. Journal of women's health, 19(11), 2017-2031.

35. Shamu, S., Abrahams, N., Temmerman, M., Musekiwa, A., \& Zarowsky, C. (2011). A systematic review of African studies on intimate partner violence against pregnant women: prevalence and risk factors. PloS one, 6(3), e17591.

36. Sigalla, G. N., Rasch, V., Gammeltoft, T., Meyrowitsch, D. W., Rogathi, J., Manongi, R., \& Mushi, D. (2017). Social support and intimate partner violence during pregnancy among women attending antenatal care in Moshi Municipality, Northern Tanzania. BMC Public Health, 17(1), 240.

37. Spangaro, J. M., Zwi, A. B., Poulos, R. G., \& Man, W. (2010). Who tells and what happens: disclosure and health service responses to screening for intimate partner violence. Health \& Social Care in the Community, 18(6), 671-680.

38. Sylaska, K. M. a. E., K.M. (2014). Disclosure of intimate partner violence to informal social support network members: A review of the literature. . Trauma,Violence, and Abuse, 15(1), 3- 21.

39. UBOS. (2017). Uganda demographic and health survey 2016. Key indicators report. Kampala, Uganda: UBOS, and Rockvile, Meryland, USA: UBOS and ICF.

40. Van Parys, A.-S., Deschepper, E., Michielsen, K., Galle, A., Roelens, K., Temmerman, M., \& Verstraelen, H. (2015). Intimate partner violence and psychosocial health, a cross-sectional study in a pregnant population. BMC pregnancy and childbirth, 15(1), 278. 